\title{
Employee Retention in the VUCA World: Challenges and Strategies
}

\author{
Bandana Nayak, John Ben P
}

\begin{abstract}
Employee retention has become one of the major areas of concern for industries across the globe, considering the dynamics of the Volatile, Uncertain, Complex and Ambiguous (VUCA) business environment. Today global explosion in business creates more prospects, employees have become highly mobile and not restricting to particular job. It is universally accepted that human resources are the life-blood of any organization. In this competitive era, every organization has realised that human capital is the major source of existence, growth and excellence of any company. Employee retention is also significantly important to make the company more cost effective and save the time by avoiding frequent hire to newcomers. Moreover, it is the interest of the employer to retain and utilise the expertise of the valuable employees which further adds on to its productivity and profit. In today's global work environment, technology has improved the global job opportunities with lucrative salary packages, flexible working hours, career opportunities, better workplace environment, on-line-recruitment facility and so on. Hence, it is a high time for the employers to keep regular track of their employees' satisfaction, ambition, commitment, engagement, work-life balance and to modify the policies asper the requirement. This paper highlights various factors that can have impact on employee retention. Further, it derives a model or framework including the desired strategies which can be adopted for retaining honest, trustworthy and competent employees.
\end{abstract}

Index Terms: Employee Retention, VUCA, Strategies, Employee Engagement, Work-Life Balance

\section{INTRODUCTION}

In today's' competitive business world employee retention has become one of the most critical issues facing the corporate leaders and managers. Retaining talented employees has become the topmost priority of organizations because of the shortage of competent and trustworthy employees, increased competition, economic growth, opportunities across borders, employee attrition, high ambition of millennials etc. A major quandary for most employers is employee attrition, with the typical annual voluntary attrition rate is $13.1 \%$ in $2018-19$ in India. The major causes reported for attrition are: no freedom and creativity, over work, lack of recognition and stagnation [1]. In the light of today's economic volatility and uncertainty, retaining employees is the biggest challenge encountered by the organizations worldwide [2].

Revised Manuscript Received on August 25, 2019

Dr. Bandana Nayak, Associate Professor, Symbiosis Institute of Business Management, Bangalore, Symbiosis International (Deemed University), E-mail: dr.bandananayak@gmail.com

Dr. John Ben P, Assistant Professor, Symbiosis Institute of Business Management, Bangalore, Symbiosis International (Deemed University) E-mail: princejohnben@gmail.com

\section{LITERATURE REVIEW}

Employee retention has emerged as the focus of current business world and gets attention across the globe, predominantly it correlates with talent management programmes which sometimes cause concern to the HR personnel as the volume of research is very high [3]- [9]. A review on employee retention revels various factors of employee attrition as organizational culture, a supportive society, work-life balance, managerial structures and policies, a collegial relationship with co-workers, and access to alternate career opportunities. She has also emphasised various factors of motivation which leads to employee retention as: compensation, recognition and rewards, training and development, work environment, organizational justice, fairness and career advancement [10]. It is also suggested that the keys to retain employees are basically to offer competitive compensation, ensure employee recognition, offer career growth and development opportunities and ensure a healthy work-life balance [11].

Researchers found different factors for managerial and non-managerial categories influencing retention [12]. The non-management employees are influenced by corporate culture, hiring and promotions, training practices whereas management employees are influenced by hiring and promotion practices of the organization. They also found a positive reduction of non-management employee turnover on the basis of organisational mission, goals and direction, rewards and compensation. A supportive work environment plays a crucial role in predicting employee Retention [13]. They also noticed that there is mediating role of organizational engagement among supportive work environment and employee retention. Many researchers also found a common factor as training activities influencing productivity and employee retention in different organizations [14]- [19]. Employee attrition affects organizational performance in terms of exhausting of experienced employees [19].

Employee retention is of greater concern to organizations since engaged and fully active employees are likely to perform better in their work roles, lead active and fulfilling lives [20] outside the formal organization and foster greater team building [21], [20]. 
within the confines of the organization. Satisfaction with the job causes many employees to stay [3]; this may be interpreted as saying that employees who connect well with the job, are reasonably confident about career advancement and the work environment [22] are likely to stay productive and spend more years at the same organization. This stays relevant even in demanding professions such as healthcare where paramedical support personnel work round the clock [23], [24].

Work environment has also been found to have a positive impact on retention of employees [25]. Work environment implies not only the physical ambience but also the general atmosphere that conveys warmth, friendliness, courtesy [26] and a sense of inclusiveness [27]. Work environment provides avenues for more cooperation, better sense of bonding and thus indirectly aids in employee retention: the overarching observed results pointing to a comfortable and productive employee who is likely to continue with the firm for a longer time horizon. However, what remains deciphered are the antecedents of employee retention. Hence our research paper aims to cast some light on unearthing key factors enabling employee retention.

\section{CONCEPTUAL BACKGROUND AND RESEARCH GAPS}

Employee retention is a methodological approach through which the employees are motivated to continue with the organization for the maximum period of time or until their formal tenure, in some cases. Retention is a major element of an organization's growth by proper talent management. It involves implementing integrated strategies or overhaul of systems which are directed towards increasing workplace productivity by evolving improved procedures for attracting, developing, retaining and utilizing the workforce with the required skills and aptitude to meet existing and forthcoming business needs [28]. From industry and research, clear evidence suggests that the formation of well defined organizational goals and objectives has an impact on employee retention and job productivity. Job satisfaction is important for employee retention. Many researchers have found a significant impact of corporate orientation and support on employee job satisfaction and overall commitment. Organizational support strongly influences job satisfaction and employees' commitment to their organisation [29]. The organizations can achieve their goals by using appropriate retention strategies which leads to better productivity [30], [31].

Although many researchers have revealed various strategies to enhance employee retention, still there is a noticeable attrition rate in every sector, mostly visible in IT sector. The millennials are constantly shifting across organizations. It is also observed in other age groups. This paper has tried to explore the factors affecting employee retention, based on the qualitative discussions with experts and HR managers, and to recommend various strategies to retain them.

\section{FACTORS AFFECTING EMPLOYEE RETENTION:}

Technological Changes: Technical up gradation is taking place in a rapid manner across globe in today's date. The world has become digital and new technologies are emerging at a faster pace replacing the older ones which is more visible in IT sector. An older version of an app or web application is getting upgraded approximately in every six months, which involves new ideas and skills. For e.g. Learning of new languages to build user friendly web applications. Those employees who are unable to cope up with the rapid change involving learning of new technologies chose to quit.

Better Opportunities: Once an employee is having a clear vision regarding his/her career perspective and he/she is competent enough in a particular field opts for better opportunity with higher pay scale within the organisation or outside. Hence, he prefers up gradation elsewhere to get more satisfaction and contentment.

Pay-gap between spouses: Pay-gap between spouses is leading to shifting of jobs from one place to another. Still the world is experiencing a male dominated society in most of the places. The difference in pay scale leads to disturbance between spouses. If a partner gets more salary, in most cases, the other partner tries to search for a job that pays equal or better salary. In search for a better paid job, the continuous shifting from one organization to another takes place.

Compensation and benefits: Compensation as well as benefits plays a vital role in attrition of an employee. Employees have a tendency for getting in to other jobs if they are getting good financial hike in other organisation as compared to the existing one. Along with a salary hike, if a person is getting better non-financial benefits he tries to shift. Employees may not leave the job with marginal differences in salary but if non-financial benefits, perks are very lucrative, there is more possibility to switch over.

Competition and Work Pressure: In this competitive environment the concept of 'survival of the fittest' holds good. Due to tough competition and dynamic environment, there are additional responsibilities and challenges at the workplace, entrusted to employees. Many of them are unable to shoulder the job enlargement and responsibility and hence are prone to back out.

Family Pressure: The new joiners are mostly pressurised by the family as they have educational loan burdens. Employees would like to pay off their obligations (loans, etc.) which lead them to switch over frequently from one company to other with a significant hike in package.

Job Satisfaction: Job satisfaction is very important in every sector for every employee. Job security, compensation, work itself, work culture, inter-personal relationship, career planning of the organisation mostly increases job satisfaction of employees. If the employee is satisfied with the job, there is least chance of quitting the organisation. Hence, it has to be taken care of by the management. 
Night Shift: Many employees do not prefer night shifts. Few companies are forced to assign night shift as their to them. Basically employees' productivity is low during night shift. Further, the young parents do not prefer to take up night shift as they have to take care of young offspring at home. This issue often becomes a challenge considering the dominance of nuclear families in urban geographies. Few female employees even prefer to quit the job under such tough circumstances.

Social Media: People are very active in social media in the current age. They easily get to know what their peers are doing. They get influenced by that and try to follow the same path of development. Employees get to know many job opportunities also through social media and get chance to apply out of multiple options.

Work-Life Balance: It has become essential on the part of the organization to ensure the work-life balance of its employees. Work-life balance adds value to work environment and the employee. Many organisations have started considering the employees as partners. But the organization and its ecosystem has to realise that work-life balance is essential as it reduce stress of employees and helps prevent burnout in the workplace. Employees become healthier, productive and are able to work in a more cost-effective manner.

Effective Leadership: Employees having supportive and effective leadership tend to stay longer period in the organization. Leaders who can engage their employees and give chance to proceed in career ladder able to retain their employees for more time. Leaders have to use ice-breaking techniques to retain top talent. Leaders help the employees to imbibe organisational culture. Once the employees understand the win-win game they would contribute better.

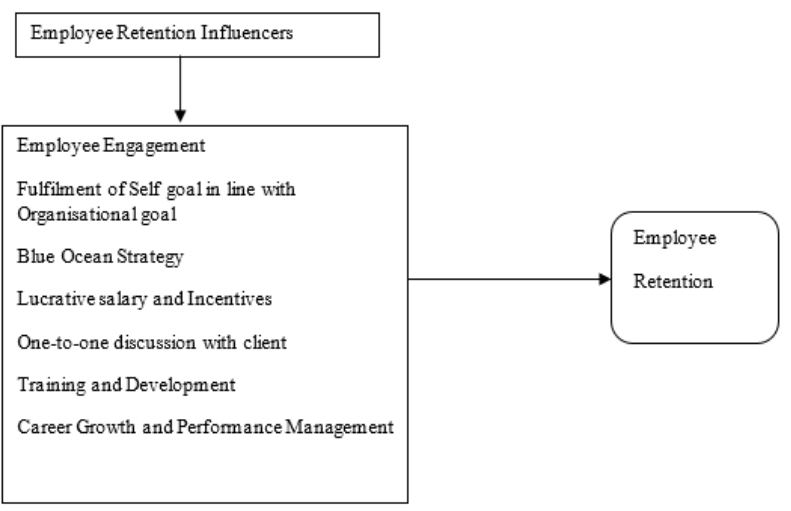

FIGURE 1: Conceptual Framework

\section{EMPLOYEE RETENTION STRATEGIES:}

Employee retention has become the major concern for organisations in the present environment. Management need to know the expectation of employees from employees' point of view. They have to make organizational strategies in line with employees' individual career strategy so that employees will be satisfied, involved and committed. While formulating employees' retention strategy, the management has to understand the explicit and implicit expectations of the employees. For example, a good compensation package, learning and development, challenging and exciting work, career growth, recognition and reward, safe and fairly good work atmosphere, autonomy etc.

\section{SUGGESTED MODEL}

The study has recommended the below model for employee retention:

In the above figure-1, a conceptual model has been proposed for the organisations to follow which would support them to retain the talented employees. Each component has been discussed below in detail:

bonding between employee and employer in any organisation. An engaged employee is one who is fully wrapped up and enthusiastic about their work and so takes positive action to promote the organisation's reputation and interest. The organisation has to involve the employees in business planning process, emphasise knowledge creation and sharing, be creative, show them the money, encourage and provide learning opportunities, create teams by business games and create excitement among employees informing upcoming opportunities.

Fulfilment of Self goal in line with Organisational goal: Organisations have to emphasise personal goal of employees and synchronise it with organisational goal and vice versa. But always employees should not be at the receiving end. A successful organisation prioritises its employees' requirement and growth plans. Then bring necessary changes to its mission and vision. Employees are the life-blood of the organisation. The management has to modify its policy accordingly.

Blue Ocean Strategy: Blue ocean strategy in HR means providing unfamiliar types of salary and pay scale structure, new types of benefits, new untested module of training method for employees. A blue ocean HR strategy will entail the adoption of creative ideas rather than mimicking other HR strategies and policies. It calls for departments to explore those hidden demands and needs of employees of the organization and try to give them something that transcends the employees' expectations. By this the organisation can retain its quality employees.

Lucrative salary and Incentives: Salary being a hygienic factor of motivation adds value to no-dissatisfaction, which is very important in the present world. The mindset of people is changing gradually. In the initial job life, lucrative salary and incentives motivates a lot which gradually transform to hygienic factor.

One-to-one discussion with client: More often there is a communication gap between the management and employees regarding the exact requirement of client. Therefore, if the company gives chance to every employee to converse directly with client and understand the real expectations, then a sense of responsibility and involvement will increase. Employee can think as an important and a strategic partner of the organisation and internal conflict also will reduce. 
Training and Development: It is very expensive and difficult for employees to pursue new knowledge, new techniques that come to the market. However, it may be relatively for the organizations which are already well versed with the ecosystem to offer opportunities for development and enhancement of the employees. The organisation has to organise, conduct and impart various updated skills and knowledge in an inexpensive and proficient way so that it will motivate the employees and improve competency. The opportunity to learn new skills is a strong reason to stay longer.

Career Growth and Performance Management: Proper career planning has to be prepared by the organisation as per the need and expectation of the employees. Sometimes the employees are unaware about the new emergent forms of knowledge and its scope. While designing training modules, career growth must be attached to it to encourage the employees. There should be career conversion also. Employer has to engage employees with short career conversions regularly and iteratively, rather than waiting until the annual development review. Performance management also influence employee retention. A good performance management process not only rewards and encourages the employees but also it retains good employees.

\section{FUTURE RESEARCH DIRECTIONS:}

Firstly, organizational forms are constantly changing; new age firms sprout overnight and are quickly taken over or acquired or absorbed into larger octopus like organizations; this is true for firms that have been merged into CISCO, for instance. Going forward researchers may spend more time understanding how employees can be retained considering the velocity of change in organizations. This is true in the Indian start-up scenario wherein the likes of Tiny Owl, Food Panda and others have become defunct or been merged into larger organizations. Under such situations how does one study employee retention? Should researchers trace the careers of people who clung on to the firms till the firms were no more? Or should research understand drivers of employee retention in entrepreneurial, new-age firms considering the volatile work environment? Several questions remain unanswered.

Secondly, considering the nature of hyper competitive industries, what are those new factors that come into play that would influence retention positively? For instance, is a retention strategy in a non-profit organization different from that of a public sector enterprise? If so the underlying constructs and tenets are of interest to a researcher. It also implies that in sectors where jobs vanish overnight, like in the case of Deutsche Bank, which lay off 18000 employees within a few days [32], the question of employee retention may be of no relevance at all. In such cases, research may shift direction to study the analogies with the punctuated equilibrium model, which discusses the industries going through cycles of steady-volatile-steady time frames over several decades. Similarly, the careers of individuals may go through such crests and troughs: researchers' interests may now be gainfully employed in understanding such concerns
Thirdly, the choices for individuals have changed [33], in the new age, options are not limited by geography, education, race or gender in several industries. Considering these in context, what can organizations do to retain employees gainfully? Answers lie in a mixture of flexible work conditions, appropriate pay scales and opportunities for reasonably rapid career advancements. In parallel, organizations have recourse to many thousands prospective candidates who may be aspiring to join them, yet are working or unemployed elsewhere at any given point in time; under these situations, what are the responsibilities of organized enterprises themselves? Should organizations stop caring about retaining existing employees? How can they draft their policies in such contexts? Hence, the VUCA (Volatile, Uncertain, Complex and Ambiguous) world itself has thrown open several new challenges to organizations.

\section{CONCLUSION}

Towards the end, potential challenges would also arise in social norms and values - for instance, in the United Kingdom, people prefer to postpone marriage, resulting in a higher employable population. People are also comfortable in 'temp' (or temporary) jobs which may mean that their expectations in terms of longer tenure is falling. As India emulates western practices, such phenomena may transpire across Indian firms, a decade from now; this in turn would lead to issues of employee retention reducing in significance. With hyper-competition, jobs in the dynamic industries such as Information technology may be driven more by Artificial Intelligence and computer aided technologies, resulting in requirement of talent of a higher order. The flip side is that such talent is likely to be fickle and mercurial in nature and employers may find it difficult to retain them. Hence, in closing, we conclude by re-stating the complexity of the problem and hope that industry practitioners find a host of flexible solutions that address the VUCA world.

\section{REFERENCES}

1. https://indianexpress.com/article/jobs/things-that-bosses-do-to-makeemployees-quit/

2. Pfeffer, J., Competitive Advantage through People: Unleashing the Power of the Workforce, Harvard Business School Press, Boston, MA, 1994.

3. Mitchell, T.R., Holtom, B.C. and Lee, T.W., How to keep your best employees: Developing an effective retention policy, Academy of Management Perspectives, 15(4), 2001, pp.96-108.

4. Law, A., "The aging workforce raises new talent management issues for employers", Journal of Organizational Excellence, Vol. 23, 2003, pp. 55-66.

5. Maria-Luisa, S., "A talent management strategy for the Justice Institute of BC”, MAI 42/06, P. 2003, Royal Roads University, Victoria, December.

6. Deloitte, "Becoming a magnet for talent", Global Talent Pulse Survey Results 2005, pp. 1-12, available at: www.deloitte.com/dtt/cda/doc/...0edition\%2C\%20Magnet $\% 20$ for $\%$ 20talent-7.FINAL.pdf (accessed April 3, 2007)

7. Buenger, V., "Talent management systems: best practices in technology solutions for recruitment, retention and workforce planning”, Human Resource Management, Vol. 45 No. 2, 2006, pp. 279. 
8. Gallagher, D.R., Nadarajah, P. and Pinnuck, M.,"Top management turnover: an examination of portfolio holdings and fund performance", Australian Journal of Management, Vol. 31 No. 2, 2006, pp. 265-93.

9. Rothberg, D.,"Survey: talent management a top concern", IT Management from CIOInsight.com, 2007, pp. 1-3, available at: www.eweek.com/article2/0,1895,2078486,00.asp (accessed January 2, 2007.

10. Dhillon, Manju, "Employee Retention - A Real Time Challenges in Indian IT Sector", IJRDO-Journal of Business Management, 3 (8), 2017, pp.229-240, ISSN:2455-6661.

11. Manhertz, Huntley, "Worldwide Trends in Employee Retention: How to Keep Your Best Employees in Any Market", Archive Global, World headquarters, 2011, Tampa, Florida, USA.

12. Moncarz, Elisa, Zaho, Jinlin and Kay, Christine," An exploratory study of US lodging properties' organizational practices on employee turnover retention", International Journal of Contemporary Hospitality Management, Vol.21, No.4, 2009, Pp.437-458, ISSN:0959-6119.

13. Kundu, Subhash, C. and Lata, Kusum, "Effects of supportive work environment on employee retention: Mediating role of organizational engagement" International Journal of Organizational Analysis, 25 (4) 2017, pp. 703-722 ISSN: 1934-8835.

14. Kallenberg, A. and Moody, J. (1994), "Human resource managemen and organizational performance", American Behavioral Scientist, 37 (7), pp. 948-62.

15. Huselid, M.A., "The impact of human resource management practices on turnover, productivity and corporate financial performance", Academy of Management Journal, 38 (3),1995, pp. 635-72.

16. Delery, J.E. and Doty, D., "Modes of theorizing in strategic human resource management: tests of universalistic, contingency, and configuration performance predictions", Academy of Management Journal, 39(4), 1996, pp. 802-35.

17. MacDuffie, J.,"Human resource bundles and manufacturing performance: organizational logic and flexible production systems in the world auto industry", Industrial and Labor Relations Review, 48 (2), 1995, pp. 197-221

18. Shaw, J., Delery, J., Jenkins, G. Jr and Gupta, N., "An organization-level analysis of voluntary and involuntary turnover", Academy of Management Journal, 41 (5), 1998, pp. 511-26.

19. Walsh, K. and Taylor, M.S., "Developing in-house careers and retaining management talent: What hospitality professionals want from their jobs", Cornell Hotel and Administration Quarterly, 48 (2), 2007 pp.163-182.

20. Wrzesniewski, A. and Dutton, J.E., "Crafting a job: Revisioning employees as active crafters of their work". Academy of management Review, 26(2), 2001, pp.179-201.

21. Bolino, M.C. and Turnley, W.H.,'Going the extra mile: Cultivating and managing employee citizenship behavior. Academy of Management Perspectives, 17(3), 2003, pp.60-71

22. Ramlall, S., "A review of employee motivation theories and their implications for employee retention within organizations". Journal of American Academy of Business, 5(1/2), 2004, pp.52-63.

23. Perrachione, B.A., Rosser, V.J. and Petersen, G.J.,"Why Do They Stay? Elementary Teachers' Perceptions of Job Satisfaction and Retention". Professional Educator, 32(2), 2008.

24. Cowin, L., "The effects of nurses' job satisfaction on retention: An Australian perspective. JONA: The Journal of Nursing Administration, 32(5), 2002, pp.283-291

25. Shields, M.A. and Ward, M., "Improving Nurse Retention in The National Health Service in England: The Impact of Job Satisfaction On Intentions to Quit", Journal of Health Economics, 20(5), 2001, pp.677-701.

26. Zeytinoglu, I.U. and Denton, M., "Satisfied workers, retained workers Effects of work and work environment on homecare workers' job satisfaction, stress, physical health, and retention". Ottawa: Research Institute for Quantitative Studies in Economics and Population, McMaster University, 2006.

27. Gopinath, R., "Employees' emotions in workplace", Research Journal of Business Management, 5(1), 2011, pp.1-15.

28. Ashikali,T.and Groeneved, S., "Diversity management in public organizations and its effect on employees: The role of transformationa leadership and the inclusiveness of the organizational culture", Review of Public Personnel Administration, 35(2), 2015.

29. Lockwood, N.R. (2006), "Talent Management: Driver for Organizational Success", Retrieved on 11th Jan 2013, from: www.shrm.org: www.shrm.org/Research/Articles/Articles/.../0606RQuartpdf.pfd

30. Susskind, A., Brochgrevink, C., Kacmar, K. and Brymer, R. (2000), "Customer service employees' behavioral attitudes: an examination",
International Journal of Hospitality Management, Vol. 19 No. 1, pp. 53-77.

31. Taplin, I.M., Winterton, J., Winterton, R., "Understanding Labour Turnover in a Labour Intensive Industry: Evidence from British Clothing Industry", Journal of Management Studies, 40(4), 2004.

32. Amadasu, D.E., "Personnel and the Nigerian Management Crisis: Ajaokuta Iron and Still Mill Examined", Abuja Management Review, 1(4), 2003.

33. Tom Sims, Paulina Duran, Sumeet Chatterjee and Matt ScuffhamBig ax falls as Deutsche Bank to lay off 18,000 in $\$ 8.3$ billion 'reinvention', 2019 , Retrieved

from

https://www.reuters.com/article/us-deutsche-bank-strategy/axe-falls-a s-deutsche-bank-lays-off-18000-in-8-3-billion-reinvention-idUSKCN 1U309P. Accessed on 8 July 2019.

34. Boswell, W.R., Roehling, M.V., LePine, M.A. and Moynihan, L.M. "Individual job-choice decisions and the impact of job attributes and recruitment practices: A longitudinal field study". Human Resource Management: Published in Cooperation with the School of Business Administration, The University of Michigan and in alliance with the Society of Human Resources Management, 42(1), 2003, pp.23-37.

\section{AUTHORS PROFILE}

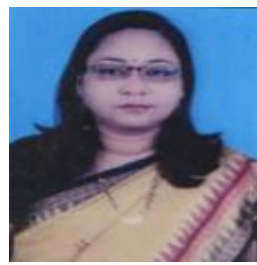

Dr. (Mrs.) Bandana Nayak is an Associate Professor at Symbiosis Institute of Busines Management, a constituent of Symbiosis International (Deemed) University. She has been teaching for the last twenty-one years in different B'Schools. Previously she worked in industry. She has completed a major research project sponsored by AICTE, New Delhi, under Research Promotion Scheme. As a committed academician and prolific writer, Dr.Nayak has 30 national and International research publications and two books to her credit She has been a consultant to Odisha Pisci Culture Development Corporation (OPDC), Department of Public Enterprise, Govt.of Odisha and a trainer to L\&T,Mysore, Department of Water Resources, Govt. of Odisha. Her area of interest is Human Resource Management, Leadership, Employee Motivation, Organizational Citizenship Behaviour etc.

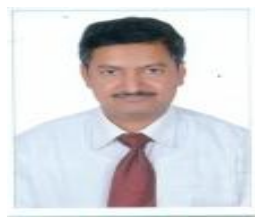

Dr. John Ben $\mathrm{P}$ is an Assistant Professor at Symbiosis Institute of Business Management, constituent of Symbiosis International (Deemed) University. He has been teaching for the last seven years. Previously he worked in several organizations for about ten years. His work experience spans automobile industry and appare retailing. In the automobile firm, he was mainly associated with lean initiatives and their implementation on the shop floor. At retailing firms, he was predominantly involved in various supply chain activities for brands. He teaches subjects such as operations management, total quality management and technology and innovation management. He has published papers in reputed journals and has attended international conferences. 